American Journal of Pharmaceutical Education 2019; 83 (10) Article 837719.

\title{
COMMENTARY
}

\section{The Need for Disruptive Innovation in Pharmacy}

\author{
Naser Z. Alsharif, PhD \\ Creighton University, School of Pharmacy and Health Professions, Omaha, Nebraska \\ Submitted June 6, 2019; accepted August 9, 2019; published December 2019.
}

Disruptive innovation became a buzz phrase in the mid-1990s in the business world. In this commentary, the application of this term to pharmacy within the context of the current status of pharmacy education and practice, highlighting barriers, discussing requirements, and identifying implications for future innovative opportunities in pharmacy is discussed.

Keywords: disruptive innovation, pharmacy education, pharmacy practice, advocacy, media.

\section{INTRODUCTION}

Disruptive innovation ${ }^{1}$ is a buzz phrase that was coined in the mid-1990s by Clayton Christensen at the Harvard Business School, who defined it as "an innovation that helps create a new market and value network that eventually disrupts existing products and services." ${ }^{1}$ In the business world, a new company can start at the bottom of a market and then determinedly gain more and more of the market, ultimately displacing established competitors. Certainly, in business, higher education and health care, disruptive innovation is needed to meet the evolving complex needs of society and the advances in technology. The 2016 ACPE standard 4.3 emphasizes innovation and entrepreneurship as an important outcome in the process of personal and professional development of pharmacy graduates, requiring that the graduate "is able to engage in innovative activities by using creative thinking to envision better ways of accomplishing professional goals." With the increased number of pharmacy schools, the increase in the number of graduates, the debate about the cost and value of higher education, the use of robotics, the delayed retirement of pharmacists, and reimbursement challenges, graduates are faced with decreased job opportunities. Thus, pharmacy educators and pharmacists should be actively engaged in disruptive innovation to meet the challenges of the marketplace. They must find new and creative uses of resources and interrupt current processes and activities that do not advance the practice.

While innovation can certainly lift the pharmacy profession to new heights, insensitive and fast innovation can alienate current practitioners, new graduates, the public, insurance companies, other members of the healthcare

Corresponding Author: Naser Z. Alsharif, School of Pharmacy and Health Professions, Creighton University, 2500 California Plaza, Omaha, NE 68178. Tel: 402-280-1857. Fax: 402-280-1883. Email: nalshari@creighton.edu. team, and other key stakeholders. This was the case when the profession shifted to the Doctor of Pharmacy (PharmD) program. In the process, this alienated baccalaureateeducated pharmacists and created disillusions ${ }^{3}$ in the minds of new graduates because of the lack of job opportunities that matched their expanded knowledge and skills. This also produced turf conflicts and stressful relationships among baccalaureate-educated pharmacists and PharmDs, ${ }^{3}$ and with physicians. After attending a workshop by Dr. Christensen with other pharmacy leaders in 2012, Lucinda Maine, $\mathrm{PhD}$, Executive Vice President and CEO of the American Association of Colleges of Pharmacy (AACP), discussed disruptive innovation as it pertains to the association and emphasized the importance of trust and building strong relationships in the process of disruptive innovation. ${ }^{4}$ She also challenged AACP members to think about this within the context of what we do at our own institutions. In this commentary, we further explore disruptive innovation within pharmacy, and the current status of pharmacy education and practice.

While the ultimate goal is to change the current status of education and practice and create new job opportunities and practice models for pharmacists to improve the health of society, the disruptive goal is not about displacement or "extinguishing" institutions or individuals. In contrast to the definition provided for business above, the disruptive goal should be as Dr. Maine shared, to "build trust and strong relationships"4 among pharmacy educators, practitioners, researchers, professional pharmacy organizations, and regulatory bodies, and as well as with other health care professionals, insurance companies, and national and federal institutions, so that the ultimate goal is achieved. This would also require empowering current and future educators, pharmacy researchers, and practitioners; improving on and transforming current practices; and maintaining respect for traditional functions conducted by pharmacists. Keeping in mind that the basic purpose of 


\section{American Journal of Pharmaceutical Education 2019; 83 (10) Article 837719.}

pharmacy is to "optimize medication use and improve patient health," students, educators, researchers, and practitioners should be encouraged to think outside of the box. They should question current practices, identify what needs to be done within the profession and for all stakeholders, establish and assess indicators of quality, and work collaboratively with colleagues within the profession and all key stakeholders to provide innovative services and drug discoveries meeting the needs of their patients and society at large. ${ }^{1,6}$

Many barriers to disruptive innovation in health care, including pharmacy, have been identified in the literature. ${ }^{1,7,17}$ These include professional factors such as inadequate education and training, ${ }^{7-12}$ lack of mutual partnership between academia and practice or with healthcare organizations, ${ }^{8-10}$ rigid accreditation standards or regulations, ${ }^{8,10,13,14}$ resistance by other health care professionals and organizations, ${ }^{10,14-17}$ the dispensing image of pharmacy in the minds of stakeholders, and lack of leadership or champions. ${ }^{1,13,14}$ Personal and logistical factors such as graduates' continued disillusions and lack of job opportunities, ${ }^{10,11,18}$ existing culture, ${ }^{1,7,15,17}$ lack of appreciation for the role of current practitioners, time and financial constraints, and lack of incentives can also serve as barriers to disruptive innovation. ${ }^{1,7,14,17}$

To address the above barriers, pharmacy academia and practice should purposefully and diligently seek to improve on the current practices to improve on the educational process, how we market our graduates and services, and the implementation of new practice models for our services.

In education, this should start with the admission process, by going beyond the need to meet enrollment quotas and seeking out exemplary students while implementing innovative and creative ways to meet budgetary needs. We should identify students who possess key personal and behavioral characteristics, a solid commitment to pharmacy, and a desire to be leaders and innovators. ${ }^{8}$ Well-planned recruitment programs for high school and college students should be conducted by energetic pharmacy educators and preceptors. Encouraging and supporting health sciences clubs that provide students with exposure to advanced clinical pharmacy settings is one major endeavor that can be done to achieve the above. Strengthening and developing the self-identify of admitted students through professionalization, leadership, and service opportunities is also essential. Pharmacy student accountability for unprofessional behavior, and pursuit of academic excellence and school and community involvement should be enforced to counter the "sense of entitlement," blank stares, uncomfortable silences, and the "cram, pass, and dump" learning occurring in pharmacy classrooms around the country. In addition, the didactic and experiential curriculum, as well as residency training programs, should stress and foster innovative thinking. This would include entrepreneurial orientation, critical thinking, finding a niche and/or new unmet services in different practice settings, discovering new models of practice based on pharmacy theories, creating new job opportunities, identifying efficient workflow, and implementing a collaborative practice. Preceptors internal or external to the institution should be role models and be made accountable to challenge students to meet educational outcomes and be innovative. Professional and graduate training, especially in the social and administrative disciplines, should emphasize the affective domain with the respective feelings, emotions, and attitudes which ultimately result in an ethical and moral practitioner who values and characterizes what pharmacy as a profession should be and prepares the innovative leaders of the future. Innovative scholarly work in all pharmacy disciplines including the biomedical sciences, pharmaceutical sciences, clinical sciences, social and administrative sciences, and the scholarship of teaching and learning is crucial to providing evidence-based education and practice to evolve the profession to higher levels and ultimately improve on current services provided and enhancing innovations. Leadership, marketing and management courses can play an important role in much of the above, including an emphasis on strategies to market professional services and establishing a patient-oriented image for pharmacy practice.

In practice, resources should be provided so that pharmacists in all practice settings have more latitude and time, and are provided incentives to innovate. At the individual level, pharmacists should value their profession and the role they play as part of the pharmacy and health care team. Pharmacists should project a positive image on a daily basis and develop confidence in their contribution and the contributions of their pharmacy colleagues. In addition, the profession should concentrate on meeting the needs of society based on existing or expanded scope of practice, especially those which are not met by physicians and other healthcare professionals. Further, embracing the value-added culture and seeking to document patient outcome is of great importance. Related to this is conducting clinical research, which can contribute to enhancing drug therapy and treatment guidelines for key disease states. Finally, the practice environment should continue to empower a positive self-identity for pharmacists, with administrators in all pharmacy settings advocating for their employees, highlighting their contributions, and ensuring support at all levels of their practice, regardless of the setting. Accountability for professional behavior 


\section{American Journal of Pharmaceutical Education 2019; 83 (10) Article 837719.}

and more purposeful and stringent continuing professional development should also be implemented.

In addition to the above, there are several overarching musts for disruptive pharmacy education and practice which are outlined here. First, it is important to exhibit intraprofessional sensitivity "to emphasize the importance for pharmacy academics interns, graduates, and practitioners to be sensitized to and aware of the diverse roles and contributions of individuals and professionals within pharmacy and to seek to communicate and collaborate with them to optimize the educational process and patient care." 19 Developing trust and strong relationships, ${ }^{4}$ respect and care among academics and practitioners is key to foster a positive environment for creativity and innovation. Second, it is important for pharmacists to respect the covenant in the relationship with patients and seek to honor it in all practice settings. ${ }^{20}$ A major aspect of that is exhibiting cultural sensitivity, ${ }^{21-23}$ providing patient-centered care and simplifying the process of care for the patient. Third, it is important to be involved in advocacy. Both academia and practice should work closely with the Accreditation Council for Pharmacy Education (ACPE) ${ }^{24}$ while ensuring quality, to allow for flexibility in the educational process to encourage innovation and meet the future demands of the practice. ${ }^{7,8}$ In addition, academia, professional pharmacy organizations, and regulatory bodies should work collaboratively and diligently to enhance the scope of practice for pharmacists, technician roles and to seek the provider status. Collaboration with healthcare systems to create collaborative and interprofessional models of practice is also needed, while respecting the culture of both organizations and not compromising the educational process. At all the levels above, in the minds of the public and in social media platforms, a major emphasis should be disrupting the image of pharmacists as pill dispensers by challenging the stereotypical representation of pharmacists in the media. We must highlight the importance of traditional services that pharmacists perform while ensuring that the public and other stakeholders are informed about the advanced services pharmacists provide with the goal of optimizing individual patient care and the health of society at large. Fourth, dynamic key end points must be established for disruptive innovation in pharmacy that are in line with changes in our health care system such as: developing new innovative drug therapies and treatment guidelines based on pharmacy theories and rigorous research; leading in the area of precision medicine, telepharmacy and home pharmacy; enhancing life expectancy, improving quality of life, and decreasing health care disparities; shifting from the image of pharmacist as drug dispenser to the image of pharmacist as drug expert; improving professional representation and increasing visibility of pharmacists in American popular culture and social media; decreasing the costs of services and drugs; expanding pharmacist representation and influence in federal agencies, other governmental agencies, and representative bodies in charge of health policy; consistently implementing the pharmacist patient care process (PPCP) nationally and recognition and acceptance of the PPCP by key stakeholder. ${ }^{25}$

\section{CONCLUSION}

Pharmacy as a profession is no stranger to innovations in education and practice..$^{7,9,10,25,26}$ The shift in academia to the PharmD degree, distance education, adopting active instructional methodologies, and use of technology are such examples. In practice, the list is extensive, including the introduction of the pharmaceutical care concept, decentralized pharmacists, drug information centers, prescriptive authority in the Indian Health Services, establishment of the Board of Pharmacy Specialties, pharmacokinetic services, pharmacoeconomics, anticoagulant clinics, medication therapy management, collaborative agreements, provider status efforts, creation of many new job opportunities (eg, ambulatory care, emergency department, operating room, transplant center, wellness care) and specialty practice (eg, hemophilia, hepatitis C, psoriasis, pulmonary hypertension, and rheumatoid arthritis). Despite the above, Dr. Maine pointed out that Dr. Christensen shared during the presentation to pharmacy leaders that in his book, The Innovator's Prescription, ${ }^{1}$ he overlooked, for example, medication management as a disruptive innovation and was not aware of the important role pharmacists play in delivering this service. Thus, to meet the challenges identified above, including the lack of appreciation of the professional and clinical training of pharmacy graduates and the role they play in optimizing drug therapy and the health of society, a true culture of disruptive innovation could re-energize the profession and address key barriers which will advance the profession and its practitioners for the rest of the 21 st century, into the $22^{\text {nd }}$ century and beyond.

\section{REFERENCES}

1. Christensen CM, Grossman JH, Hwang J, eds. The Innovator's Prescription: A Disruptive Solution for Health Care. New York: McGraw-Hill; 2009.

2. Accreditation Council for Pharmacy Education. Accreditation standards and key elements for the professional program in pharmacy leading to the doctor of pharmacy degree ("Standards 2016"). https:// www.acpeaccredit.org/pdf/Standards2016FINAL.pdf. Published February 2, 2015. Accessed May 27, 2019.

3. Alsharif N Z, Roche V, Murray WJ. Making pharmaceutical care work. US Pharmacist. October, 1999.

4. Maine LM. An era of disruptive innovation and opportunity. Am J Pharm Educ. 2012;76(7):Article 123. 


\section{American Journal of Pharmaceutical Education 2019; 83 (10) Article 837719.}

5. American Pharmacists Association. Vision and mission for pharmacy. 2011. www.pharmacist.com/vision-and-missionpharmacy-profession. Accessed May 27, 2019.

6. Dyer J, Gregersen HB, Christensen CM. The Innovator's DNA: Mastering the Five Skills of Disruptive Innovators. Boston, MA: Harvard Business Review Press; 2011.

7. Blouin RA et al. Role of innovation in education delivery. Am J Pharm Educ. 2009;73(8):Article 154.

8. Svensson CK, Ascione FJ, Bauman JL, et al. Are we producing innovators and leaders or change resisters and followers? Am J Pharm Edu. 2012;76(7):Article 124.

9. Kennerly J, Weber RJ. Role of pharmacy education in growing the pharmacy practice model. Hosp Pharm. 2013;48(4):338-342. https:// www.ncbi.nlm.nih.gov/pmc/articles/PMC3839450/. Accessed July 13, 2019.

10. Cubbins PO, Micek ST, Badowski M, et al. Innovation in clinical pharmacy and opportunities for academic-practice partnership.

Pharmacotherapy. 2014; 34(5):345-e354.

11. Sharp A. Job market showing demand for specialized pharmacists. Health eCareers. https://www.healthecareers.com/ article/healthcare-news/job-market-showing-demand-forspecialized-pharmacists. Published February 23, 2017. Accessed July 13, 2019.

12. Fjortoft N, Gettig J, Verdone M. Teaching innovation and creativity, or teaching to the test? Am J Pharm Educ. 2018;82(10):Article 7423.

13. Robinson CR, Smith MD. Overhauling the delivery system: costreducing innovation in health care. Health Affairs. 27(5). https://

www.healthaffairs.org/doi/full/10.1377/hlthaff.27.5.1353. Published September/October 2008. Accessed July 13, 2019.

14. Rick T. Top 30+ key obstacles to innovation. @MELIORATE. http://www.torbenrick.eu/t/r/let. Published September 5, 2014.

Accessed July 13, 2019.

15. Jensen K. Is health care ready for disruptive innovation? (part two). The Health Professions Network. https://hpnonline.org/ishealth-care-ready-for-disruptive-innovation-part-two/. Published June 22, 2017. Accessed July 13, 2019.
16. Herzlinger RE. Why innovation in health care is so hard. Harvard Business Rev. https://hbr.org/2006/05/why-innovation-inhealth-care-is-so-hard. Published May 2006. Accessed July 13, 2019. 17. Christensen CM, Bohmer RMJ, Kenagy J. Will disruptive innovations cure health care? Harvard Business Rev. https://hbr.org/ 2006/05/why-innovation-in-health-care-is-so-hard. Published September-October 2000. Accessed July 13, 2019.

18. Brown DL. A looming joblessness crisis for new pharmacy graduates and the implications it holds for the academy. Am J Pharm Educ. 2013;77(5):Article 90.

19. Alsharif NZ. Intraprofessional sensitivity: a must for the academy and the profession. Am J Pharm Educ. 2013;77(3):Article 42.

20. American Pharmacists Association. Code of ethics for pharmacists. https://www.pharmacist.com/code-ethics. Accessed May 27, 2019

21. O'Connell MB, Korner EJ, Rickles NM, Sias JJ. Cultural competence in health care and its implications for pharmacy. Part 1: Overview of key concepts in multicultural health care.

Pharmacotherapy. 2007;27:1062-1079.

22. O'Connell MB, Rickles NM, Sias JJ, Korner EJ. Cultural competency in health care and its implications for pharmacy. Part 2: Emphasis on pharmacy systems and practice. Pharmacotherapy. 2009;29:14e-34e.

23. O'Connell MB, Rodriguez de Bittner M, Poirier T, et al. Cultural competency in health care and its implications for pharmacy part 3A: emphasis on pharmacy education, curriculums, and future directions. Pharmacotherapy. 2013;33:e347-367.

24. Accreditation Council for Pharmacy Education. https:// www.acpe-accredit.org/. Accessed May 27, 2019.

25. Joint Commission of Pharmacy Practitioners. Pharmacists' Patient Care Process. http://www.pharmacist.com/sites/default/files/ files/PatientCareProcess.pdf. Published May 29, 2014. Accessed May 27, 2019.

26. Cain J. A pharmacy elective course on creative thinking, innovation and TED Talks. Am J Pharm Educ. 2015;80(10):

Article 170. 